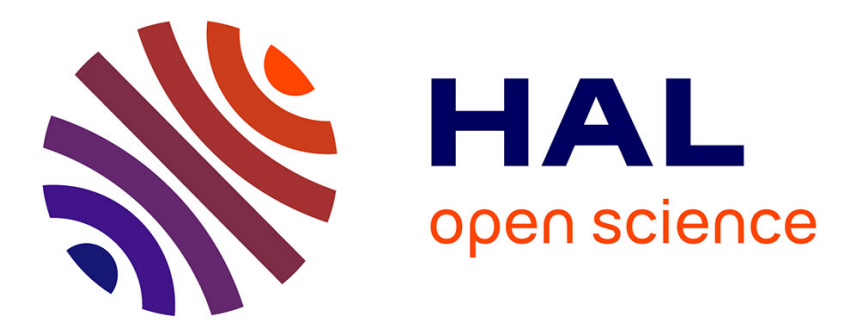

\title{
Experimental investigation and computer simulation of thermal behaviour of wallboards containing a Phase Change Materiel
}

\author{
Maha Ahmad, André Bontemps, Hébert Sallée, Daniel Quénard
}

\section{To cite this version:}

Maha Ahmad, André Bontemps, Hébert Sallée, Daniel Quénard. Experimental investigation and computer simulation of thermal behaviour of wallboards containing a Phase Change Materiel. Energy and Buildings, 2005, 38 (4), pp.357-366. 10.1016/j.enbuild.2005.07.008 . hal-00184235

\author{
HAL Id: hal-00184235 \\ https://hal.science/hal-00184235
}

Submitted on 11 Feb 2020

HAL is a multi-disciplinary open access archive for the deposit and dissemination of scientific research documents, whether they are published or not. The documents may come from teaching and research institutions in France or abroad, or from public or private research centers.
L'archive ouverte pluridisciplinaire HAL, est destinée au dépôt et à la diffusion de documents scientifiques de niveau recherche, publiés ou non, émanant des établissements d'enseignement et de recherche français ou étrangers, des laboratoires publics ou privés. 


\title{
Experimental investigation and computer simulation of thermal behaviour of wallboards containing a phase change material
}

\author{
Maha Ahmad $^{\mathrm{a}, *}$, André Bontemps ${ }^{\mathrm{b}}$, Hébert Sallée ${ }^{\mathrm{a}}$, Daniel Quenard ${ }^{\mathrm{a}}$ \\ ${ }^{a}$ Centre Scientifique et Technique du Bâtiment, CSTB, 24, Rue Joseph Fourier, Saint Martin d'Hères, France \\ ${ }^{\mathrm{b}}$ Université Joseph Fourier, LEGI/GRETh, 17, Avenue des Martyrs, 38054 Grenoble Cedex, France
}

In the objective to define passive components for the light envelope of buildings, different types of wallboards containing a phase change material (PCM) were studied. The high storage capacity should enable the overall thickness of wallboards to be less than $5 \mathrm{~cm}$. To lower the investment costs, the wallboards were made from commercial panels after a first attempt of using gypsum walls. Three types of wallboards were studied: (i) a polycarbonate panel filled with paraffin granulates; (ii) a polycarbonate panel filled with polyethylene glycol PEG 600; (iii) a PVC panel filled with PEG 600 and coupled to a VIP. An experimental set-up was built to determine the thermal response of these wallboards to thermal solicitations. Experimental results were compared to those obtained by a numerical simulation in which an apparent heat capacity method was used. The final results show that the last studied wallboard could be used in the test cells under construction and then validate the concept.

Keywords: Latent heat storage; Phase change material; PCM; Vacuum insulated panel; VIP; Wallboard; Light envelope

\section{Introduction}

Thermal storage is an attractive way to manage thermal energy. It allows production to be adapted to needs and creates favourable conditions by realising a constant relationship between required and available energy. In addition, in a building, the storage can effectively contribute to improve the comfort of occupants. This comfort is not only function of the surrounding air temperature and humidity but also of the wallboard temperature. A closed space is comfortable if the temperature and the relative humidity are within given parameters. These values must have smallest variations in space, from side to side of a room and from a room to the other and as a function of time during the whole day or from a season to the following. For these reasons, the houses with very thick walls are found, especially comfortable, cold in summer and hot in winter, due to their capacity to store thermal energy under the form of sensible heat. Most modern buildings use light construction and to achieve such comfort conditions in a less massive construction, one can implement materials containing phase change materials (PCMs) capable of storing thermal energy as latent heat. An additional advantage is that the indoor

\footnotetext{
* Corresponding author.

E-mail address: m.ahmad@cstb.fr (M. Ahmad).
}

walls can be kept at a constant temperature corresponding to the phase change temperature of the PCM. This temperature can be chosen in choosing the PCM. This process helps the human body to keep its temperature in equilibrium not only with the ambient air but also with the wall surfaces, thus, creating the most favourable conditions for maximal comfort.

The use of PCMs in passive and active solar buildings has received considerable interest since the first published application in 1940. The energy storage by wallboards being of particular importance to store and recover solar energy, many applications have been considered and some can be found in Refs. [1-5]. Up to now, using PCMs in building materials was limited by the difficulty of incorporating the PCM into the wallboard. A new technique of packaging this type of material in form of granulates could allow us an easier handling, and the use and performance of such granulates were compared to those of a PCM conditioned in a more traditional way.

The whole study will consist of three steps: thermal characterisation of materials, study of the behaviour of the wallboards during a thermal cycle and study of test cells made of these wallboards and submitted to climatic variations.

This paper describes part of the first two steps of the study and aims to compare the use of several kinds of PCM with different packaging to make a choice. Three types of samples were studied: (i) a gypsum-based wallboard in which 


\section{Nomenclature}

\section{Latin letters}

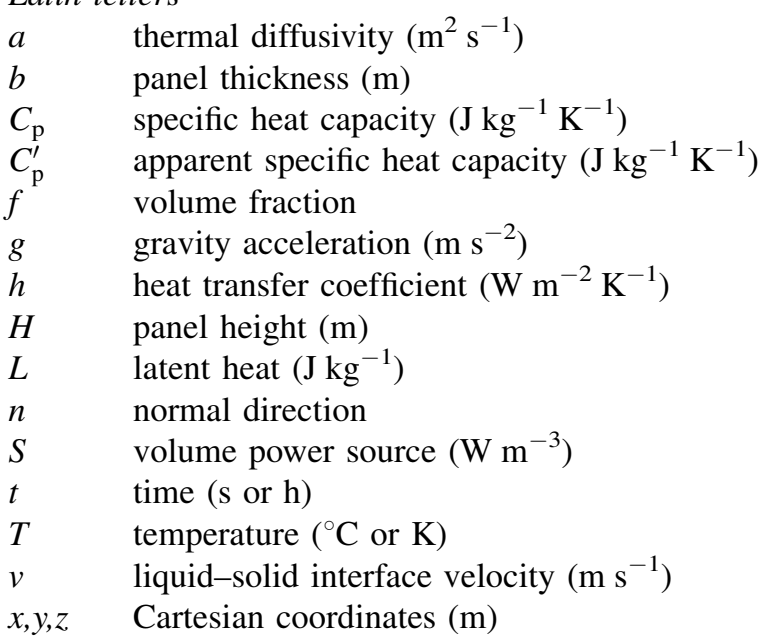

Greek letters

$\beta \quad$ volumetric expansion

$\varphi \quad$ heat flux $\left(\mathrm{W} \mathrm{m}^{-2}\right)$

$\lambda$ thermal conductivity $\left(\mathrm{W} \mathrm{m}^{-1} \mathrm{~K}^{-1}\right)$

$v \quad$ kinematic viscosity $\left(\mathrm{m}^{2} \mathrm{~s}^{-1}\right)$

$\omega \quad$ pulsation $\left(\mathrm{s}^{-1}\right.$ or $\left.\mathrm{h}^{-1}\right)$

$\rho \quad$ density $\left(\mathrm{kg} \mathrm{m}^{-3}\right)$

$\tau \quad$ period (s or h)

\section{Dimensionless number}

$\mathrm{Ra} \quad$ Rayleigh number

\section{Subscripts}

$\begin{array}{ll}e & \text { external, outdoor } \\ i & \text { internal, indoor } \\ l & \text { liquid } \\ m & \text { mixture } \\ s e & \text { outdoor surface } \\ s i & \text { indoor surface } \\ s & \text { solid }\end{array}$

granulates containing paraffin are incorporated; (ii) a wallboard constituted of polycarbonate panels filled with same granulates; (iii) a wallboard made of polyvinyl chloride (PVC) panels filled with polyethylene glycol (PEG). Parallel to this experimental work, a numerical study was carried out to investigate properties and possible configurations of wallboards containing gypsum, PCMs and insulating materials. In particular, the thickness and the arrangement of the insulating material relatively to the PCM were investigated.

\section{Theoretical background}

The problem to solve is the heat transfer across a vertical panel whose material can change of phase. In the case of phase change, it is necessary to know whether natural convection takes place or not. This can be identified through the Rayleigh number defined as:

$R a=\frac{g \beta\left(T_{\mathrm{H}}-T_{\mathrm{C}}\right) H^{3}}{\nu a}$

where $T_{\mathrm{H}}-T_{\mathrm{C}}$ is the temperature difference between the hot and the cold side and $H$ is the panel height. It has been shown by Jany and Bejan [6] that in an enclosure of thickness $b$, the convection regime does exist if

$R a^{1 / 4}<\frac{b}{H}$

Due to the small thickness of the wallboards $(<6 \mathrm{~cm})$ and heights higher than $1 \mathrm{~m}$, this condition is fulfilled for the used material (polyethylene glycol) and only heat transfer by conduction will be considered. With usual notations, the local equation of the energy balance is:

$\left(\rho C_{\mathrm{p}}\right) \frac{\partial T_{\mathrm{s}}}{\partial t}=\operatorname{div}(\lambda \overrightarrow{\operatorname{grad}} T)+S$

In the right terms, $S$ is the internal heat power generated inside the material. In the case of a solid-liquid phase change, the two following situations can be found according to the mode of incorporation and the type of the PCM.

\subsection{Considering a liquid-solid interface: phase change at a given temperature}

If the displacement of a liquid-solid interface is considered, for pure material for example, two conduction equations are required, one for each single phase region bounded by the moving interface:

$$
\begin{aligned}
& \left(\rho C_{\mathrm{p}}\right)_{\mathrm{s}} \frac{\partial T_{\mathrm{s}}}{\partial t}=\operatorname{div}\left(\lambda_{\mathrm{s}} \operatorname{grad} T_{\mathrm{s}}\right)+S \\
& \left(\rho C_{\mathrm{p}}\right)_{1} \frac{\partial T_{1}}{\partial t}=\operatorname{div}\left(\lambda_{1} \operatorname{grad} T_{1}\right)+S
\end{aligned}
$$

The subscripts $\mathrm{s}$ and 1 refer to the solid and liquid, respectively.The coupling is realised through the boundary conditions:

- continuity of temperature

$$
T_{\mathrm{s}}(x, y, z, t)=T_{1}(x, y, z, t)=T_{\mathrm{F}}
$$

- energy balance at the interface

$\lambda_{\mathrm{s}} \frac{\partial T_{\mathrm{s}}}{\partial n}-\lambda_{1} \frac{\partial T_{1}}{\partial n}=\rho L v_{n}$

where $\partial / \partial n$ is the derivative following a normal vector at any point of the interface and $v_{n}$ is the moving interface velocity at this point.

\subsection{Phase change within a temperature range}

This is the case when the material is made of a mixture of PCM or when particles of PCM are randomly distributed in a solid substrate. When the particles solidify or melt, they release 
or absorb thermal energy in form of latent heat. This energy is taken into account:

- either by adding a source term $S$ which is the product of the heat exchanged by a particle by the number of particles by volume unit;

- or by using an equivalent heat capacity.

These two approaches can be linked if the presence of particles does not change the direction of propagation of the heat flow. Thus, it is considered that the mixture substrate plus PCM is isotropic and homogeneous and that it has average thermophysical properties. Considering the one-dimensional case for simplicity, the heat conduction equation becomes:

$\rho_{\mathrm{m}} C_{\mathrm{pm}} \frac{\partial T}{\partial t}=\lambda_{\mathrm{m}} \frac{\partial^{2} T}{\partial x^{2}}+S(x, t)$

the subscript $\mathrm{m}$ referring to the mixture (PCM + substrate) properties.

If $f$ is the volume fraction of solid PCM, the heat power released by unit volume is:

$S=\rho L \frac{\partial f}{\partial t}$

Eqs. (7) and (8) necessitate the knowledge of the volume fraction but we can avoid it by remarking that the heat conduction equation can be rearranged under the form

$\rho_{\mathrm{m}} C_{\mathrm{pm}}^{\prime} \frac{\partial T}{\partial t}=\lambda_{\mathrm{m}} \frac{\partial^{2} T}{\partial x^{2}}$

where $C_{\mathrm{pm}}^{\prime}$ is an apparent specific heat capacity given by:

$C_{\mathrm{pm}}^{\prime}=C_{\mathrm{pm}} \mp \frac{\rho}{\rho_{\mathrm{m}}} L \frac{\partial f}{\partial T}$

It is seen that by measuring this apparent heat capacity $C_{\mathrm{pm}}^{\prime}$ as well as the effective thermal conductivity $\lambda_{\mathrm{m}}$ of the mixture, Eq. (9) can be solved without the exact knowledge of the volume fraction of PCM. Another way to solve Eq. (9) is to model this apparent heat capacity with the help of a theoretical curve.

\section{Computer simulation}

The computer simulation was carried out with the software of heat conduction "Heating" [7]. This software uses a finite difference method and treats cases with either a solid-liquid interface during the phase change or a variable heat capacity following the scheme developed in the theoretical part. This variable heat capacity was measured for gypsum/paraffin granulates mixtures. However, it appears that in modifying the shape of the heat capacity curve, results are not significantly modified. This also was remarked by Alisetti and Roy [8] who studied the influence of the heat capacity curve shape on the results and they come to the same conclusion. When the heat capacity was not measured, we used the Kondo et al. model [9] to represent it. This model seems the most accurate compared to the experimental curves.

The chosen simulation imposed a sinusoidal variation of the outdoor temperature which represents the daily variation of the atmosphere temperature. The boundary conditions are as follows:

- outdoor temperature

$$
T_{\mathrm{e}}\left({ }^{\circ} \mathrm{C}\right)=24+8 \sin (\omega t)
$$

where $t$ is the time and $\omega=2 \pi / \tau, \tau$ being the period $(24 \mathrm{~h})$. - outside heat transfer coefficient between the external surface and the atmosphere

$h_{\mathrm{e}}=17 \mathrm{~W} \mathrm{~m}^{-2} \mathrm{~K}^{-1}$

- inside heat transfer coefficient between the internal surface and the room atmosphere

$h_{\mathrm{i}}=9 \mathrm{~W} \mathrm{~m}^{-2} \mathrm{~K}^{-1}$

- indoor temperature $T_{\mathrm{i}}=23{ }^{\circ} \mathrm{C}$.

The thicknesses of the studied wallboards were determined in assuming that the solar energy provided during a half day could be stored. The three types of wallboards were studied with this simulation.

\section{Preliminary investigation: gypsum wallboards with paraffinic granulates}

Many investigations have been published on PCM impregnated gypsum (see, for example Ref. [10]). A different way was chosen and the first trial was to test the use of granulates as means of packaging PCMs. In that aim, samples constituted of a mixture of granulates containing a PCM (paraffin) and gypsum were characterised. The realised samples were constituted of a mixture of gypsum and granulates containing a PCM (paraffin) whose phase change temperature was $26^{\circ} \mathrm{C}$.

The used PCMs are supplied by the Rubitherm ${ }^{\circledR}$ company [11]. They are incorporated in granulates having a diameter of $1-3 \mathrm{~mm}$ and containing about $35 \mathrm{wt} \%$ of paraffin (Fig. 1). The chosen granulates are the GR25 which has a melting temperature of about $26^{\circ} \mathrm{C}$. To determine wallboard properties, thermal characterisation of pure gypsum, PCM/gypsum mixtures and PCM only have been undertaken

Measurements of the thermal conductivity $\lambda$ were realised with two sorts of normalised devices, a heat flow meter

Table 1

Thermal conductivity (in $\mathrm{W} \mathrm{m} \mathrm{m}^{-1} \mathrm{~K}^{-1}$ ) of gypsum, gypsum/PCM and air/PCM mixtures

\begin{tabular}{llll}
\hline Material & $T\left({ }^{\circ} \mathrm{C}\right)$ & $\lambda$ & \\
\cline { 3 - 4 } & & Experimental & Theoretical \\
\hline Gypsum & 22 & 0.34 & - \\
GR25 $(15 \%)+$ gypsum & 26.4 & 0.306 & 0.286 \\
GR25 $(90 \%)+$ air & 32.3 & 0.177 & 0.147 \\
\hline
\end{tabular}



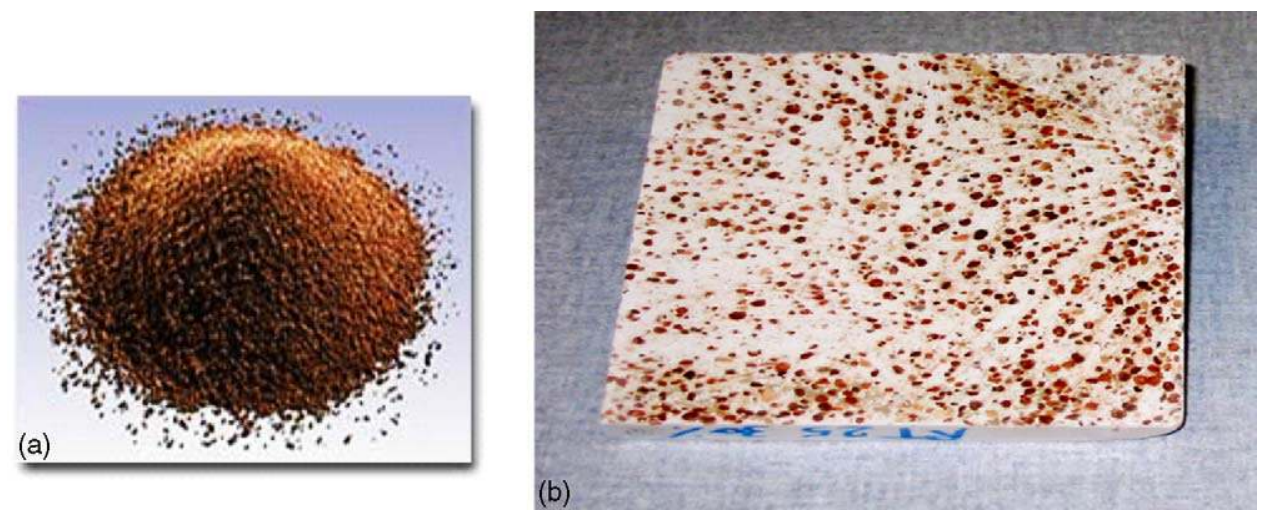

Fig. 1. (a) Granulates filled with paraffin and (b) gypsum-granulate sample.

apparatus and a guarded hot plate apparatus [12-14]. The results were compared with different classical theories. In Table 1 is shown an example where $\lambda$ was calculated for a mixture with the Maxwell-Garnett model [15] and compared with the measured values. It is seen that the theoretical values underestimate the experimental ones. This could be due to the nonuniformity of granulate diameters.

The apparent specific heat capacity was deduced from DSC measurements. As it is shown in Fig. 2, this heat capacity presents a peak near the melting temperature. The area of this peak represents the heat absorbed during the phase change and allows us to control the PCM quantity present in the sample [16].

Neeper [17] showed that for a sinusoidal variation of the indoor temperature whose amplitude is $2.76{ }^{\circ} \mathrm{C}$, the maximum storable energy is $995 \mathrm{~kJ} \mathrm{~m}^{-2}$. With the characteristic values of the gypsum/PCM samples and for a amount of 35\% of granulates, a crude estimate shows that $8 \mathrm{~cm}$ thick panel is necessary. A numerical simulation was carried out to determine the storage capacity of a wallboard during a whole day and to confirm this value. It is expected that for a given variation of the outdoor temperature, the oscillation amplitude of the indoor temperature should be strongly reduced. Moreover, comparison was made with a wallboard with the same thickness but made of pure gypsum and of a traditional insulating material. Curves presented in Fig. 3 represent the temperatures of indoor surfaces $T_{\mathrm{si}}$ of wallboards with variable thickness. In Fig. 3(a), as a reference, are presented the temperature variations of a pure gypsum wallboard with different thickness. It can be seen

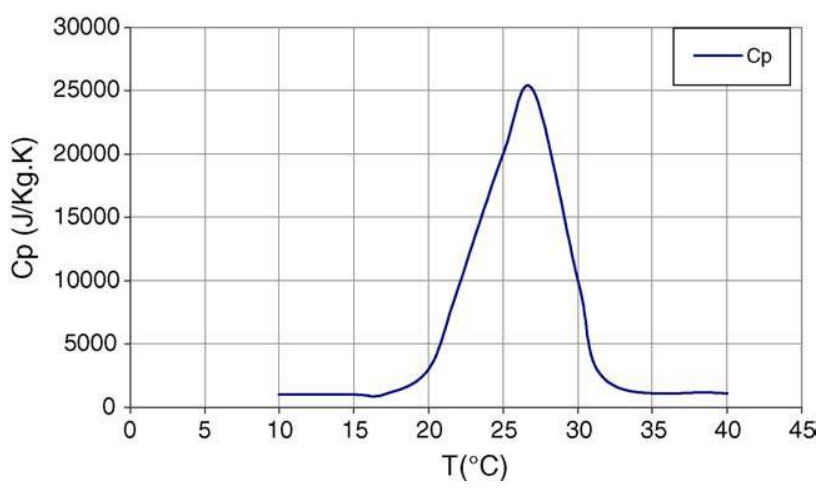

Fig. 2. Specific heat capacity of a gypsum-granulate sample measured by DSC.
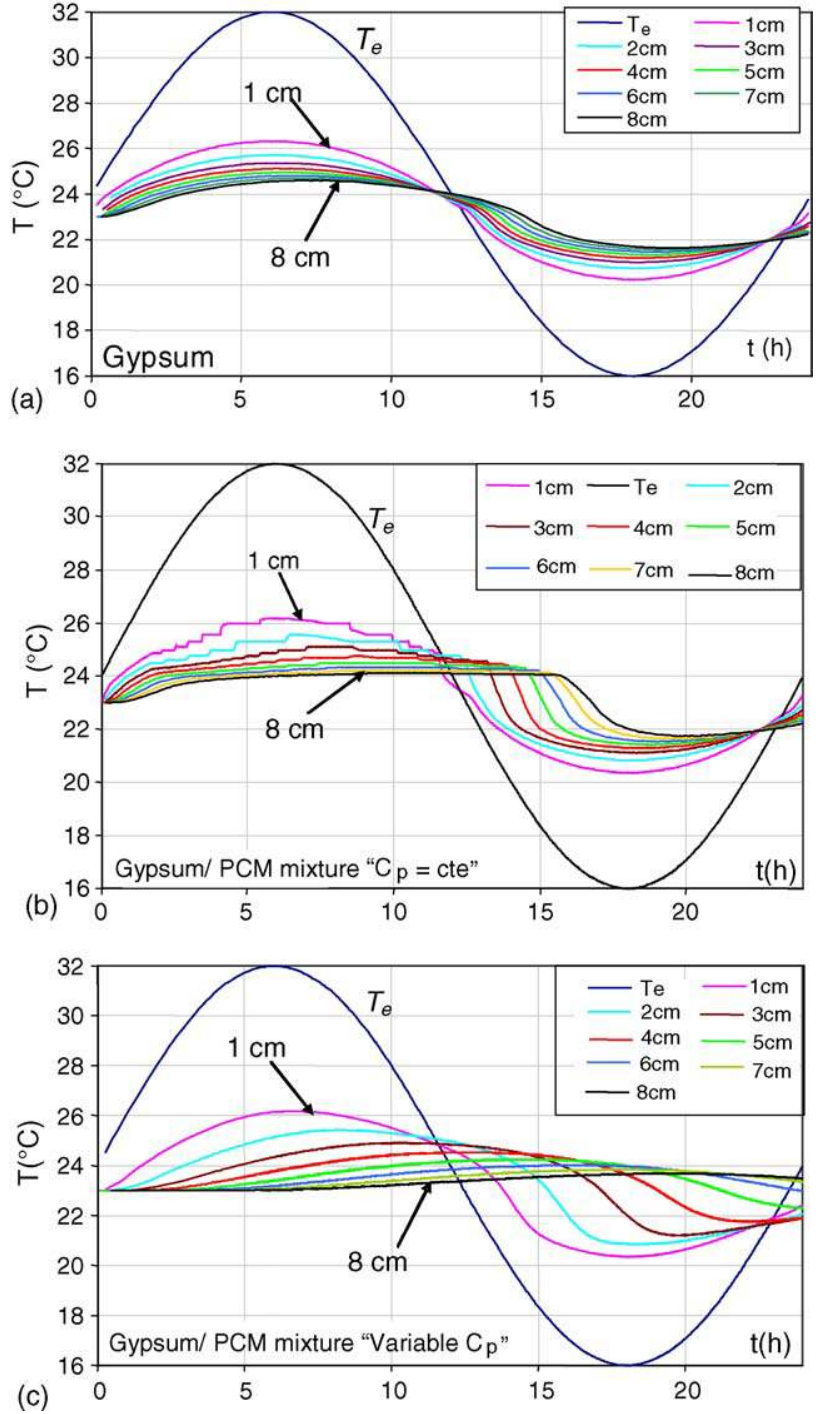

Fig. 3. Indoor surface temperature variation calculated by numerical simulation for gypsum and for PCM granulates/gypsum wallboards with different thickness: (a) pure gypsum wallboard; (b) PCM granulates/gypsum wallboard, considering a solid-liquid interface $\left(C_{\mathrm{p}}=\right.$ cte); (c) PCM granulates/ gypsum wallboard, considering an apparent specific heat capacity (variable $\left.C_{\mathrm{p}}\right)$. 


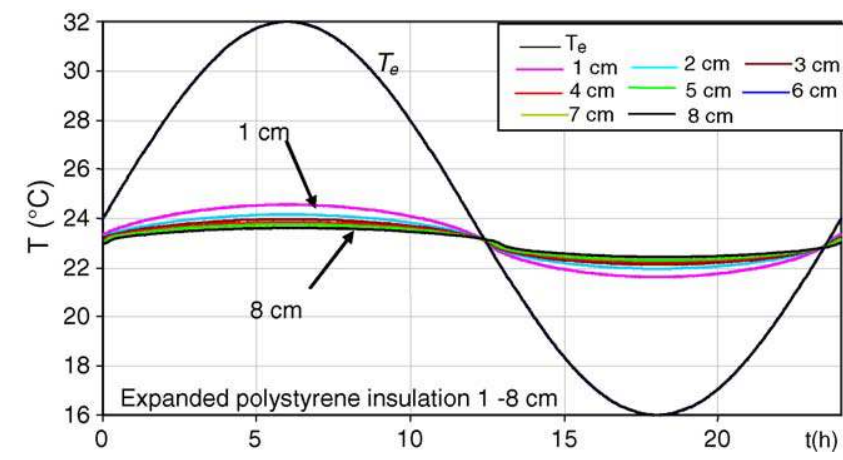

Fig. 4. Indoor surface temperature variation calculated by numerical simulation for expanded polystyrene panels with different thicknesses (insulation $=1-8 \mathrm{~cm}$ ).

that whatever the thickness, no significant time lag appears. In Fig. 3(b) are presented the temperature variations when considering that a solid-liquid interface can exist. One can observe a plateau due to the phase change (solid-liquid) as well as a sharp temperature variation due to the presence of a solidification front. In fact, it was observed that such a sharp temperature variation never occurred in any experiment. In Fig. 3(c) are presented the temperature variations when an apparent heat capacity is used. In Fig. 4 are presented the temperature variations for a wallboard made of expanded polystyrene. For the smallest thickness, the insulation material is the more efficient. For the $8 \mathrm{~cm}$ thick wallboards, the amplitudes of the temperature variation are almost the same for the insulating material and the mixture gypsum/PCM. One can see that the $T_{\mathrm{si}}$ oscillation amplitude of the gypsum/PCM wallboard varies very little for thicknesses larger than $7 \mathrm{~cm}$. In addition, the presence of PCM leads to a time lag of $T_{\mathrm{si}}$ oscillations. The gypsum/PCM wallboard becomes efficient for thickness larger than $1 \mathrm{~cm}$.

It can be observed that the presence of granulates incorporating a PCM in the wallboard does not bring a significant improvement in the attenuation of the amplitude of the temperature oscillations compared to the use of an

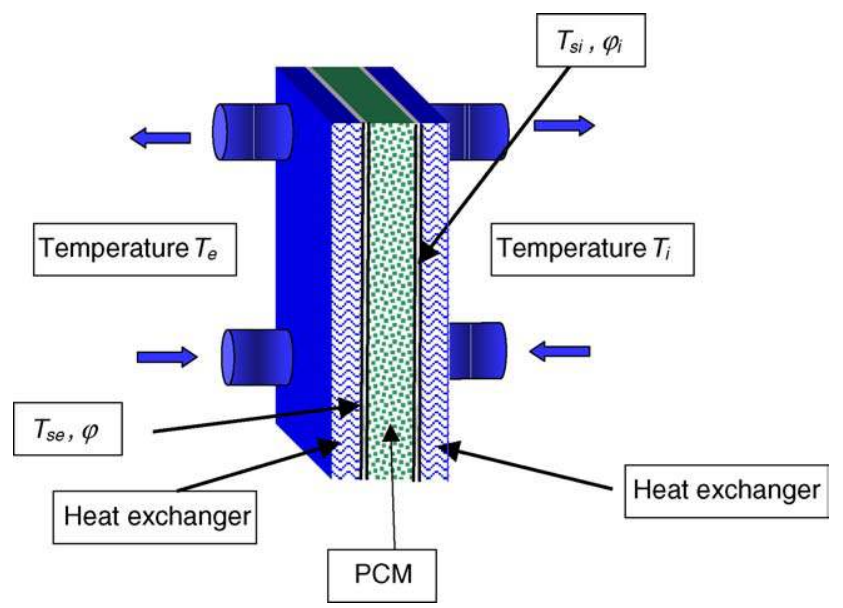

Fig. 5. Sketch of the experimental set-up.

insulating material. However, the amount of PCM available for an efficient storage is not very high and should be increased. If done, the thickness of the wallboard should be increased too much and the advantage of a light envelope would be lost. Another difficulty for such samples was the durability due to the effusion of paraffin through the granulates. These are the reasons why other types of wallboard were tested.

\section{Experimental set-up}

\subsection{Test loop}

To test thin wallboards and especially their ability to store heat and to attenuate the temperature variations, an experimental installation was realised. In this installation, the temperature on each side of a board can be imposed by a heat exchanger or the temperature on one side can be imposed, the other side being in contact with the ambient air (Fig. 5). Fig. 6 is a schematic of the test facility. Referring to this figure,

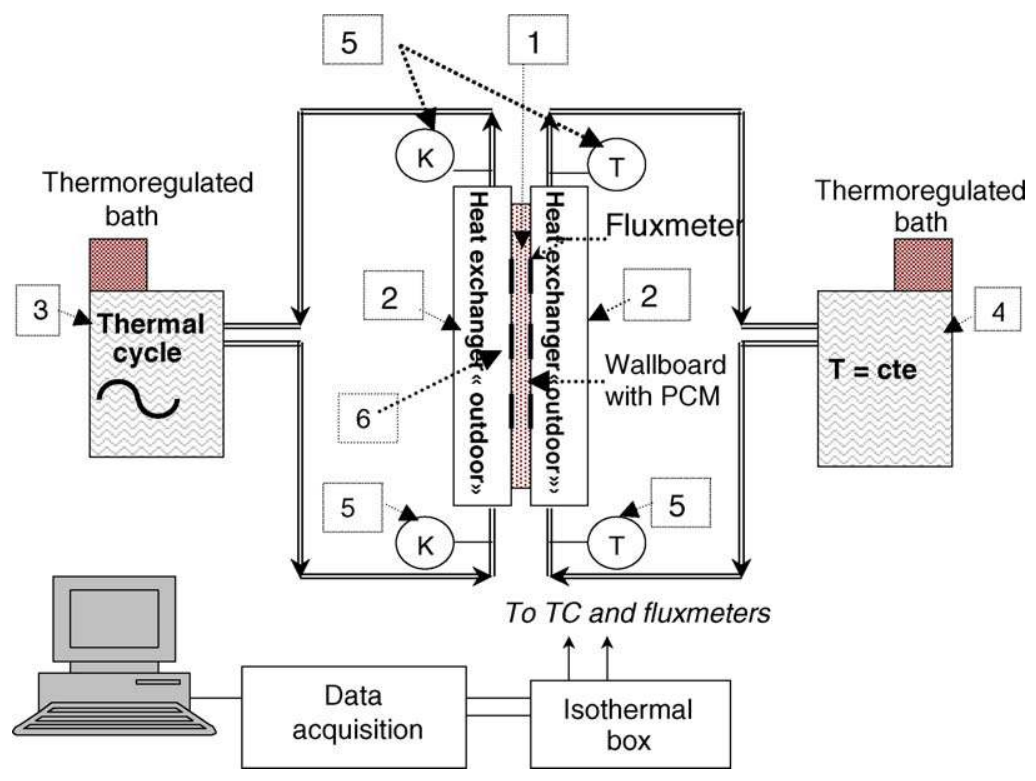

Fig. 6. Test loop schematic (see text for numbers). 


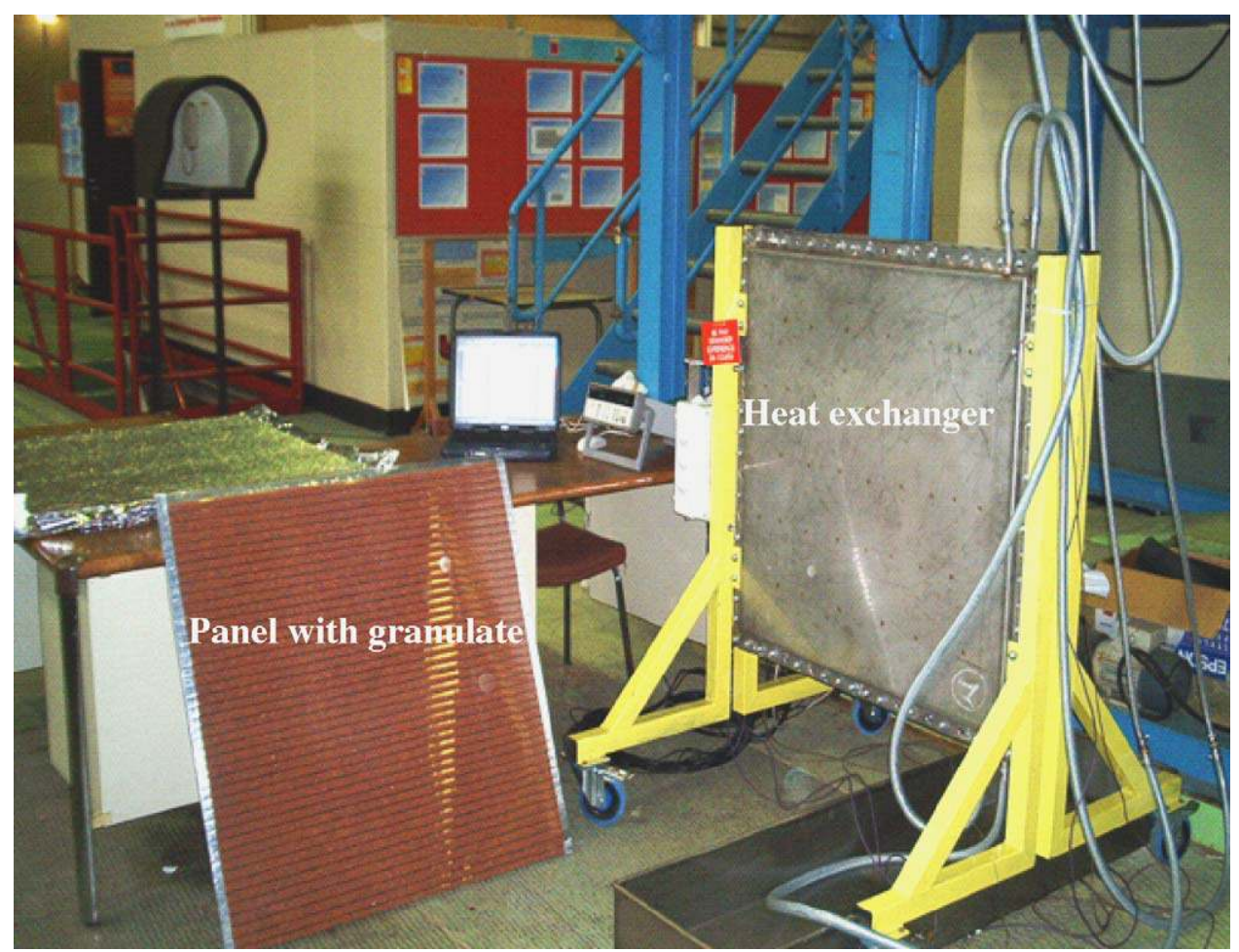

Fig. 7. View of the experimental set-up.

the wallboard (1) is located in close contact between two heat exchangers in stainless steel and (2) fed by two thermoregulated water flows. One of the thermo-regulated baths can be programmed to produce a prescribed variation of the water temperature. A sinusoidal variation was prescribed to simulate daily temperature variations. The water inlet and outlet temperatures and water flow rates were measured with four thermocouples (5) and two volumetric flow meters, respectively. Between the wallboard and each heat exchanger are placed five fluxmeters with five thermocouples (6). Thermocouples and fluxmeters were calibrated with a specific device. The fluxmeter thickness is $0.2 \mathrm{~mm}$ and a thin conductive rubber foam was placed between the panel and the heat exchangers to ensure a good thermal contact without deteriorating the fluxmeters. The temperature and heat flux curves presented in the next sections are an average of the five thermocouples or fluxmeters measurements. A view of the experimental installation is presented in Fig. 7.

\subsection{Tested panels}

To have a minimum investment and the largest diffusion, wallboards were built from commercial panels. Two types were selected: (i) one made of polycarbonate and (ii) the second made of polyvinyl chloride.

For the polycarbonate panel (16 mm thick), three tests were carried out:

- with an empty panel as a reference;

- with a panel filled with granulates;

- with a panel filled with polyethylene glycol (PEG 600).
The PCM melting temperatures are chosen in the same range, $26{ }^{\circ} \mathrm{C}$ for paraffin embedded in granulates, and a temperature ranging from 20 to $25^{\circ} \mathrm{C}$ for PEG 600. Other PCM could have been chosen but PEG 600 was used due to its availability and its low cost.

Some difficulties appeared in reliability of polycarbonate panels and $25 \mathrm{~mm}$ thick PVC panels were then used. The geometrical characteristics of the panels are given in Fig. 8. In order to manufacture the panel which will be tested on a complete test cell, a vacuum isolated panel (VIP) was coupled to the last chosen PVC panel.

\subsection{Boundary conditions}

The water flow rates were fixed sufficiently high to keep constant the wall temperatures of the heat exchangers. This
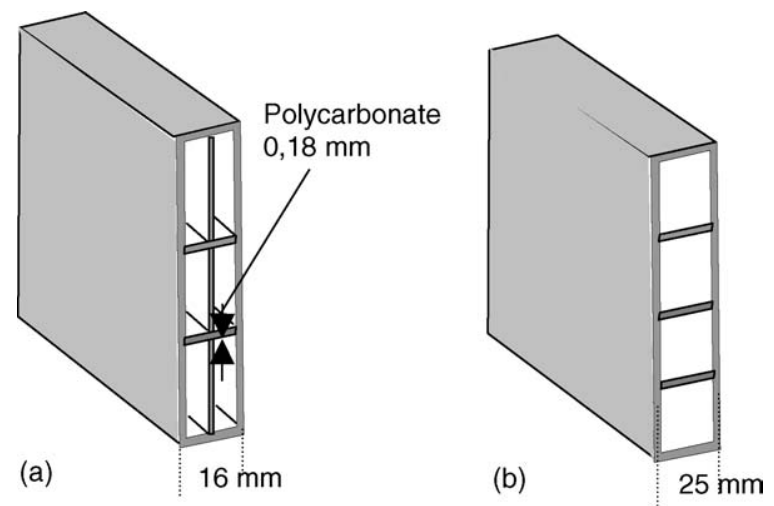

Fig. 8. Structure of tested panels: (a) polycarbonate and (b) PVC panel. 
was verified by measuring inlet and outlet temperatures of each water flow whose difference was less than $0.2{ }^{\circ} \mathrm{C}$. The temperature of one water flow was varied sinusoidal to impose a temperature condition at one wallboard surface. This side will be called the external (or outdoor) side and all the quantities referring to this side will be noted with the e subscript. A 24-h period was chosen to simulate a daily variation which has the same form as given in formula (11). On the second wallboard surface, either a constant temperature was imposed $\left(23{ }^{\circ} \mathrm{C}\right)$ or the heat exchanger was removed to have the surface temperature controlled by natural convection.

\section{Experimental results and discussion}

\subsection{Thermal cycle on an empty polycarbonate panel}

This panel was studied to validate the experimental installation together with the heat conduction software "Heating" [7] by direct comparison of experimental and numerical results. The temperature on one wallboard side is varied sinusoidally, the other is fixed at $23{ }^{\circ} \mathrm{C}$. In Fig. 9 are represented the temperature variations of the water (external temperature, $T_{\mathrm{e}}$ ), the temperature variation on the external wallboard surface (external surface temperature, $T_{\mathrm{se}}$ ) and on the internal wallboard surface (internal surface temperature, $\left.T_{\mathrm{si}}\right)$. The water temperature on the other side called internal temperature $T_{\mathrm{i}}$ is kept constant. Due to the small thickness of the panels, no lag between $T_{\mathrm{e}}$ and $T_{\mathrm{i}}$ appears. In Fig. 10 are given the heat flux variations on each side of the panel. Heat flux $\varphi_{\mathrm{e}}$ is positive when heat penetrates the panel on the external side and $\varphi_{\mathrm{i}}$ is positive when heat leaves the panel on the internal side. No time lag is apparent. As a crude estimate, this lag $\Delta t$ can be calculated with the infinite wall formula which gives (Kakaç and Yener [18]):

$\Delta t=\frac{b}{2} \sqrt{\frac{\tau}{\pi a}}$

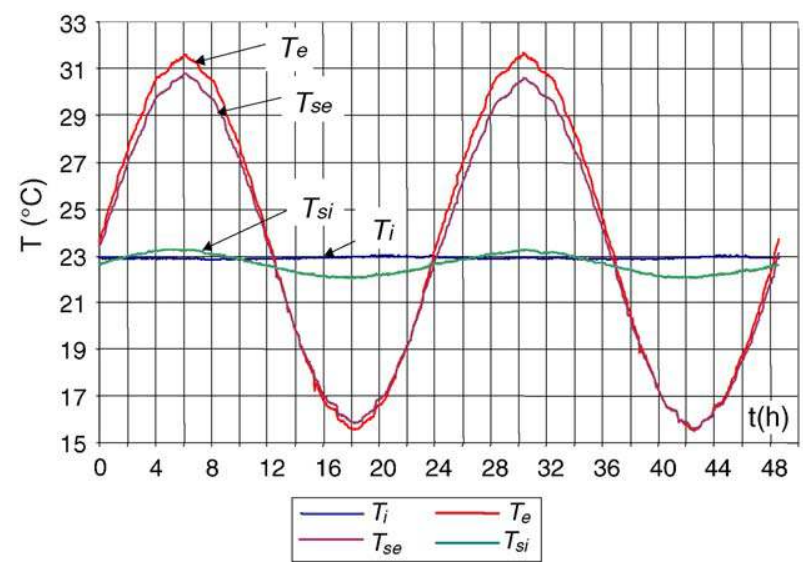

Fig. 9. Thermal cycle on an empty polycarbonate panel. Indoor and outdoor temperature variations.

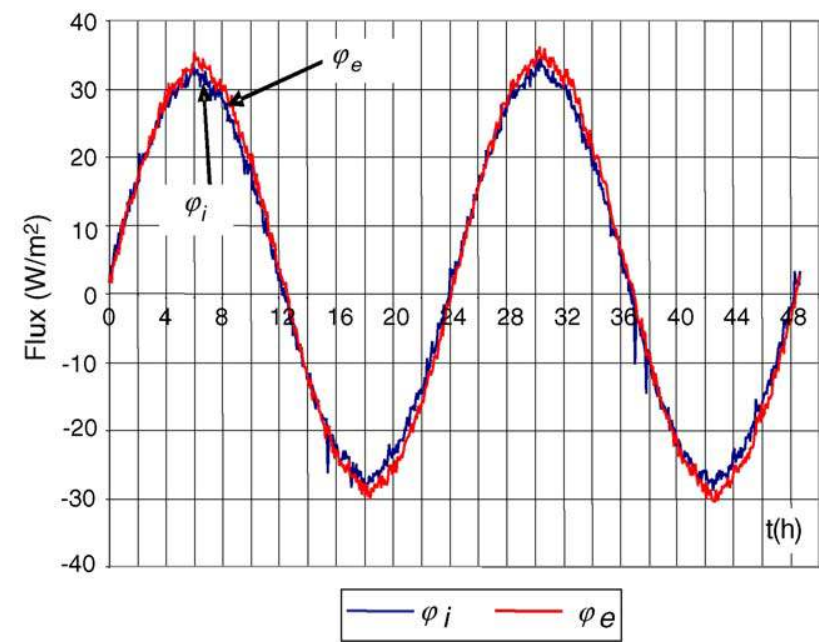

Fig. 10. Thermal cycle on an empty polycarbonate panel. Indoor and outdoor flux variations.

where $\tau$ is the period, $a$ the thermal diffusivity and $b$ is the panel thickness. Taking the air thermal diffusivity value, the lag is of the order of $5 \mathrm{mn}$ and cannot be accurately measured.

\subsection{Thermal cycle on a polycarbonate panel filled with paraffin granulates}

A similar experiment was carried out with a polycarbonate panel filled with paraffin granulates. Results are presented in Figs. 11 and 12. No significant effect due to the PCM is observed on the temperature curves. However, the heat flux curves are different from those of panels without PCM. If $\varphi_{\mathrm{e}}$ is the "external" heat flux positive when heat penetrates the panel, one can see that its variation is sinusoidal. The internal heat flux variation is slightly different. A small time lag is observed. Between 1 and $2 \mathrm{~h}$, a plateau is visible corresponding to the heat storage due to the phase change. By plotting the difference $\varphi_{\mathrm{e}}-\varphi_{\mathrm{i}}$, the heat storage can be appreciated. If $\varphi_{\mathrm{e}}-\varphi_{\mathrm{i}}$ is positive, a heat

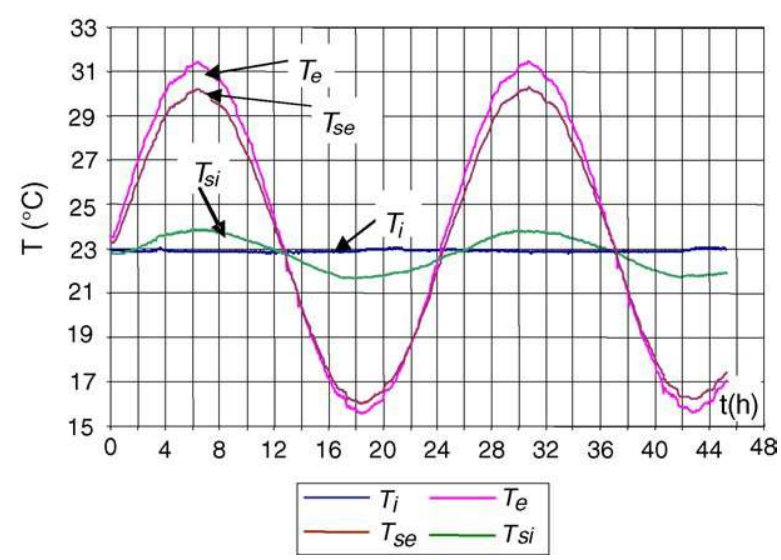

Fig. 11. Thermal cycle on a polycarbonate panel filled with PCM granulates. Variation of indoor, outdoor and surface temperatures. 


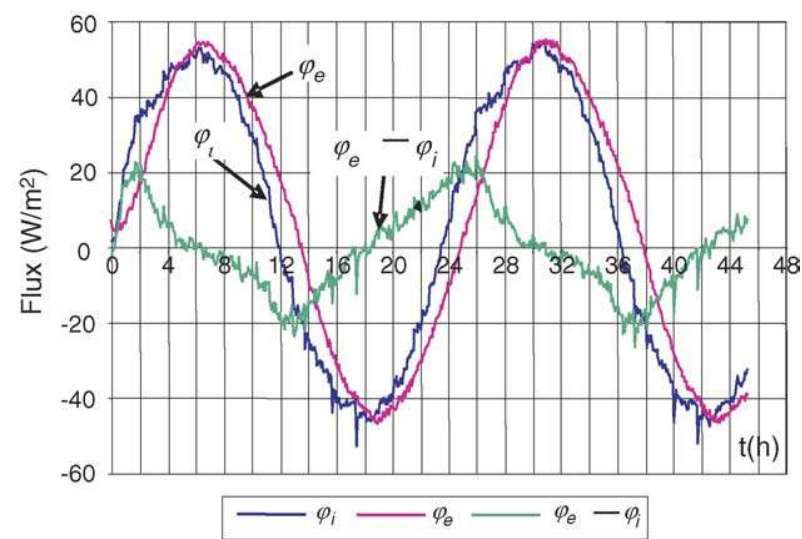

Fig. 12. Thermal cycle on a polycarbonate panel filled with PCM granulates. Variation of indoor, outdoor fluxes and of their difference.

storage takes place and conversely, if $\varphi_{\mathrm{e}}-\varphi_{\mathrm{i}}$ is negative. The stored heat is identical to the released heat as seen by the relation

$\int_{0}^{\tau}\left(\varphi_{\mathrm{e}}-\varphi_{\mathrm{i}}\right) \mathrm{d} t=0$

However, if we calculate the amount of the stored and released heat during a period (areas above or under the time axis), it is seen that their values are $308 \mathrm{~kJ}$ less than the storage capacity of the material $(375 \mathrm{~kJ})$. This is due to the low conductivity of the mixture (air + granulates) which cannot permit the heat to be transmitted easily from one side to the other.

\subsection{Polycarbonate panel filled with polyethylene glycol (PEG 600)}

To overcome the conductivity problem due to the presence of air, the polycarbonate panel was filled with PEG 600 . Although this material has a large range of phase change temperature $\left(\sim 5^{\circ} \mathrm{C}\right)$, it was chosen for its low cost and its availability. The previous thermal cycle was applied to the panel and the results are presented in Figs. 13 and 14. It is noted that in this case, the internal temperature has small variations. As seen in Fig. 13, the internal surface temperature, although

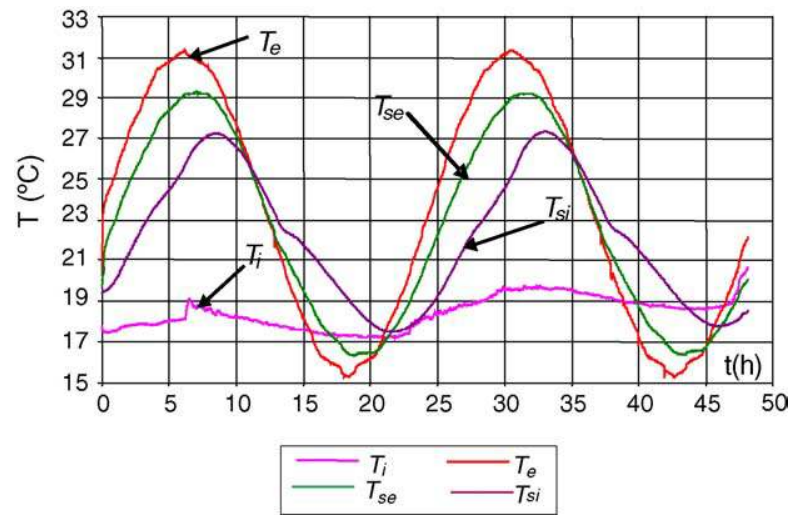

Fig. 13. Thermal cycle on a polycarbonate panel filled with PEG 600. Variation of indoor, outdoor and surface temperatures.

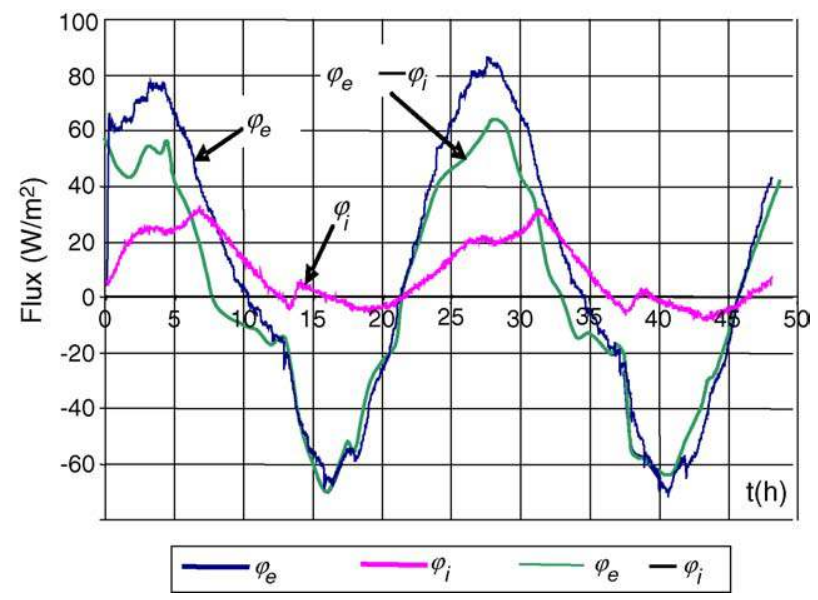

Fig. 14. Thermal cycle on a polycarbonate panel filled with PEG 600. Variation of outdoor, indoor fluxes and of their difference.

periodical, is no longer sinusoidal and presents inflexion points, clearly indicating the presence of phase change and heat storage associated with it. Moreover, a time lag of about $2.5 \mathrm{~h}$ is observed. A significant attenuation between the two amplitudes
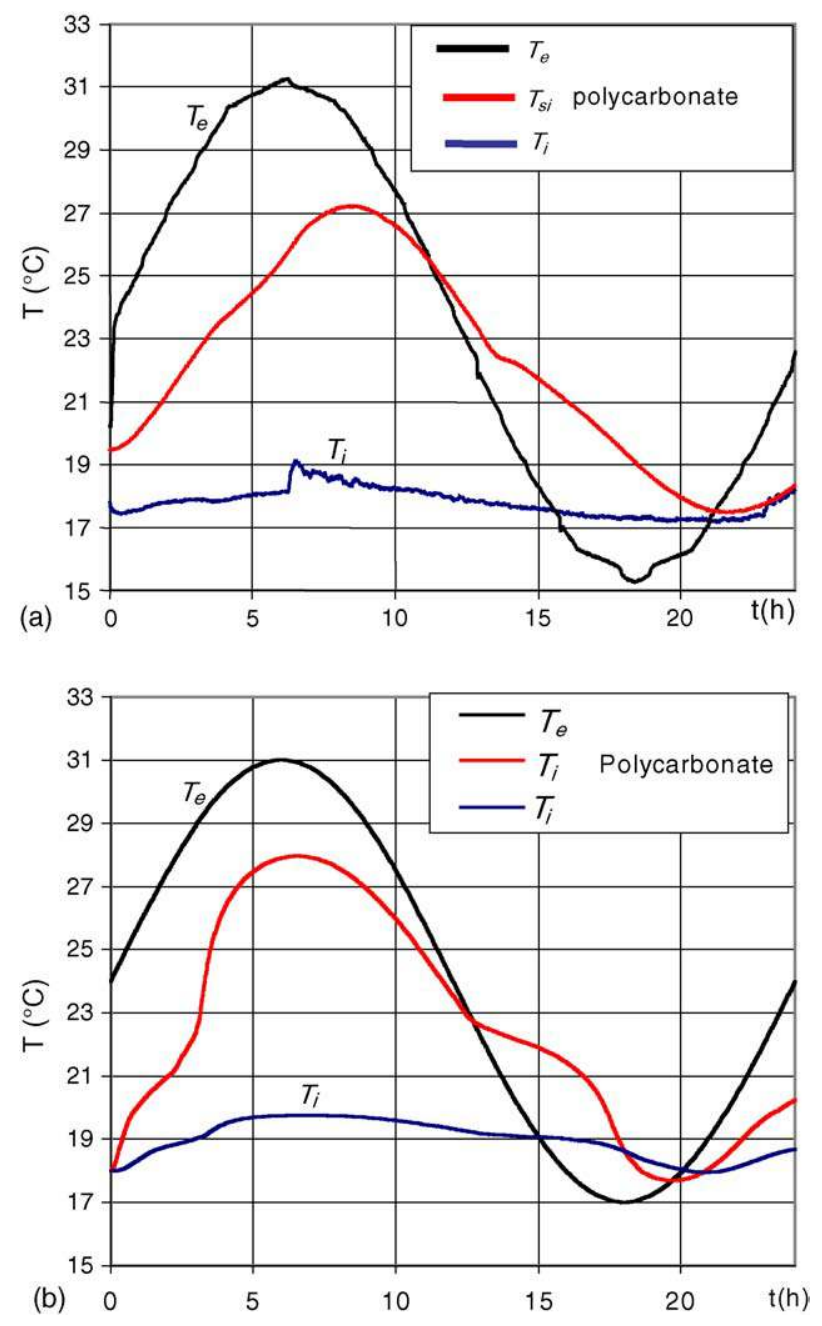

Fig. 15. Variation of outdoor and indoor surface temperatures of a polycarbonate panel filled with PEG 600: (a) experimental curve and (b) numerical simulation with an apparent heat capacity. 


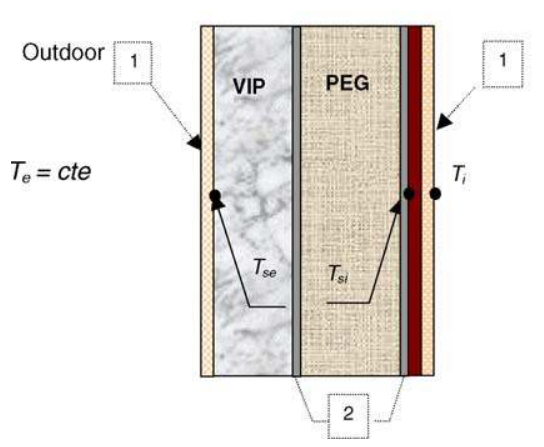

Indoor

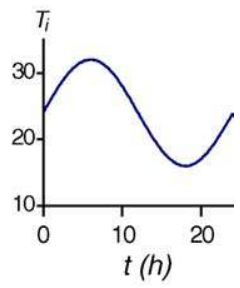

Fig. 16. Structure of a wallboard coupling PCM with VIP. Experimental boundary conditions: (1) plywood and (2) PVC.

of $T_{\mathrm{e}}$ and $T_{\mathrm{si}}$ occurs showing the damping effect of the PCM. Heat fluxes are shown in Fig. 14. By plotting $\varphi_{\mathrm{e}}-\varphi_{\mathrm{i}}$ and calculating the area between the curve and the time axis, one can see that an important storage takes place corresponding to the whole capacity of the wallboard.
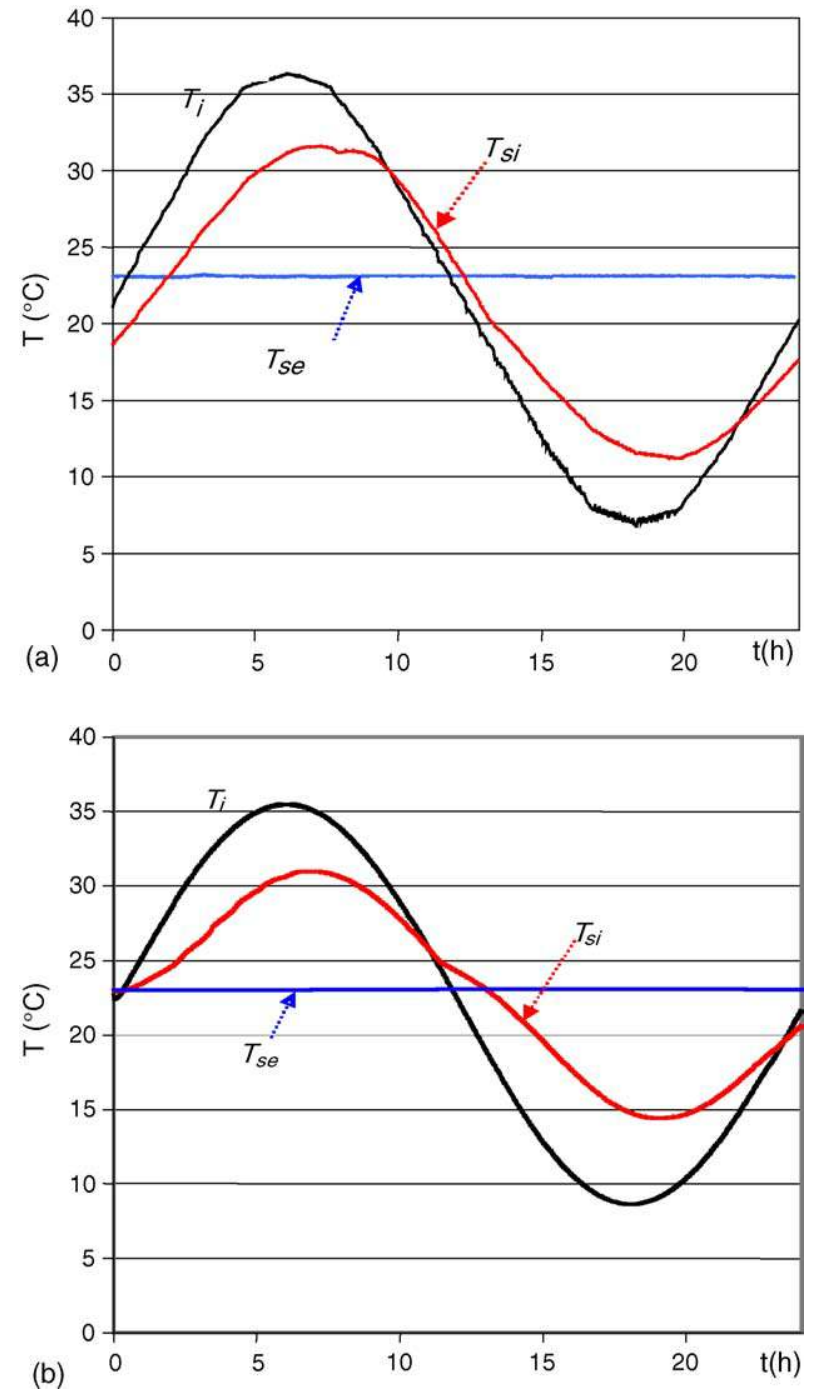

Fig. 17. Variation of indoor, outdoor and indoor surface temperatures of a wall coupling PCM (PEG 600) with VIP: (a) experimental results and (b) numerical simulation with an apparent heat capacity.
The experimental results were compared with those obtained by numerical simulation. In the "Heating" software, we used an apparent heat capacity deduced from Kondo et al. [9] model and we modelled the heat exchangers taking into account the thermal resistance due to the heat exchanger walls. In Fig. 15(a and $b$ ) are given the experimental and theoretical curves, respectively. The agreement is rather good and it is shown that the software can be used to interpret our experiments with the chosen apparent heat capacity.

However, some practical problems arose due to the phase change process. During liquefaction, many isolated liquid zones appeared in the solid material bulk whose pressure induced cracks in the panel wall. Then, another panel type was tested.

\subsection{PVC panel filled with polyethylene glycol (PEG 600)}

In this last experiment, a PVC panel was filled with PEG 600 and in order to be used in the test cells under construction, the panel was associated to a VIP. This VIP is constituted of two aluminized sheets between which silica powder is introduced after air evacuation. To rigidify the system, the VIP is placed between the PVC panel and thin plywood. The structure is shown (Fig. 16) together with the temperature boundary conditions. The temperature on the VIP side was varied $\left(T_{\mathrm{i}}\right)$ and the temperature on the other side kept constant $\left(T_{\mathrm{e}}\right)$. Experimental and theoretical results are given in Fig. 17(a and b).In the software, a variable heat capacity with the same shape as previously used was introduced and it is seen that a good agreement was obtained between experimental and theoretical curves ( $a$ and b) It is remarked that the surface temperature $T_{\mathrm{si}}$ undergoes a strong attenuation compared to $T_{\mathrm{i}}$. This can be compared to a room in which a strong amplitude oscillation of temperatures occurs, whose walls can absorb heat in decreasing the temperature amplitudes. Such wallboards withstanded overpressures due to local liquefaction and they were chosen to equip the test rooms. The numerical wallboard model with variable heat capacity can interpret the experimental results and will be used for modelling.

\section{Conclusion}

In order to build a light building envelope, an investigation was carried out to define, build and test wallboards containing a phase change material. This study constitutes the preliminary steps before construction of cells equipped with such wallboards in order to obtain a certain indoor passive air conditioning and especially to avoid overheating of buildings during summer. The prerequisite specifications were to obtain a wallboard thickness less than $5 \mathrm{~cm}$ and to choose commercial light panels to induce the lowest investment. To exploit their high heat storage capacity, these panels were filled with PCM, first with paraffin granulates, then with PEG 600.

Several tests were carried out with an experimental set-up designed for such panels. It was shown that the selected polycarbonate panels filled either with granulates or with PEG 
600 were not convenient for our purposes. PVC panels filled with PEG 600 showed properties compatible with our objective of a light envelope having a high heat capacity storage. Reliability tests have been realised and no deterioration of properties was noted after more than 400 thermal cycles. A numerical simulation was carried out with the heat conduction software "Heating" to interpret the experimental data. Using an apparent heat capacity to model the phase change allows us to obtain a good agreement between experimental and theoretical results. A new experimental work is in progress to use these wallboards in test cells.

\section{References}

[1] Y. Rabin, I. Bar-Niv, E. Korin, B. Mikic, Integrated solar collector storage system based on a salt-hydrate phase-change material, Solar Energy 55 (6) (1995) 435-444.

[2] A.K. Athienitis, C. Liu, D. Banu, D. Feldman, Investigation of the thermal performance of a passive solar test-room with wall latent heat storage, Building and Environment 32 (5) (1997) 405-410.

[3] K.A.R. Ismail, J.R. Henriquez, Thermally effective windows with moving phase change material curtains, Applied Thermal Engineering 21 (2001) 1909-1923.

[4] U. Stritih, Heat transfer enhancement in latent heat thermal storage system for buildings, Energy and Buildings 35 (2003) 1097-1104.

[5] A.M. Khudhair, M.M. Farid, A review on energy conservation in building. Applications with thermal srorage by latent heat using phase change materials, Energy Conversion and Management 45 (2004) 263-275.
[6] P. Jany, A. Bejan, Scaling theory of melting with natural convection in a enclosure, International Journal of Heat and Mass Transfer 31 (6) (1998) 1221-1235.

[7] Heating: Multidimensional, Finite-Difference Heat Conduction Analysis Code System, NEA, 1998.

[8] E.L. Alisetti, K. Roy, Forced convection heat transfer to phase change material slurries in circular ducts, Journal of Thermophysics and Heat Transfer 14 (2000) 115-118.

[9] T. Kondo, T. Ibamoto, T. Yuuji, Research on Thermal Storage of PCM Wallboard, 10, Workshop for International Energy Agency, Annex, 2000 (Japan).

[10] S. Scalat, D. Banu, D. Hawes, J. Paris, F. Haghighata, D. Feldman, Full scale thermal testing of latent heat storage in wallboard, Solar Energy Materials and Solar Cells 44 (1996) 49-61.

[11] Rubitherm ${ }^{\mathbb{R}}$, http://www.rubitherm.com.

[12] J.P. Cull, Thermal conductivity probes for rapid measurements in rock, Journal of Physics E Scientific Instruments A173 (1974) 428-450.

[13] Norme française, NF B 40-316, AFNOR, 1989, Performance thermique des matériaux et produits pour le bâtiment, Détermination de la résistance thermique par la méthode de la plaque chaude gardée et la méthode fluxmétrique, Norme française, Norme européenne, Juillet 2001, www.afnor.fr.

[14] ISO, 8894-2, Matériaux réfractaires, Détermination de la conductivité thermique, Partie 2: Méthode du fil chaud parallèle, 1990.

[15] A.W. Pratt, in: R.P. Type (Ed.), Thermal Conductivity, Academic Press, London, 1969.

[16] D. Feldman, D. Banu, DSC analysis for the evaluation of an energy storing wallboard, Thermochemica Acta 272 (1996) 243-251.

[17] D.A. Neeper, Thermal dynamic of wallboard with latent heat storage, Solar Energy 68 (2000) 393-403.

[18] S. Kakaç, Y. Yener, Heat Conduction, Hemisphere Publishing Corporation, Washington, USA, 1985. 